\title{
Supply Chain Digital Innovation in Complex Capital Projects
}

\author{
Yasmine Sabri \\ Department of Management, Economics \& Industrial Engineering \\ Politecnico di Milano \\ Milan, Italy \\ yasminesabri.hassan@polimi.it \\ Paolo Trucco \\ Department of Management, Economics \& Industrial Engineering \\ Politecnico di Milano \\ Milan, Italy \\ paolo.trucco@polimi.it \\ Ignazio Saverio Morganti \\ Department of Management, Economics \& Industrial Engineering \\ Politecnico di Milano \\ Milan, Italy \\ ignaziosaverio.morganti@mail.polimi.it
}

\begin{abstract}
The present research investigates why and how organizations are adopting digital transformation in their operations and supply chains. Following a systematic review of the literature, a novel conceptual model is developed to help the management of the transition in organizations that run complex capital projects. The conceptual model is examined and afterwards will be refined based on practitioners' feedback. The refined model is a result of crosschecking the views of senior executives in both early adopters of digitalization as well as the lagging project-based organizations. This paper is mainly reporting on the first phase of the research- that is, developing a preliminary conceptual model.
\end{abstract}

Keywords-Digital Transformation, Supply Chain Innovation, Capital Projects, Project-based.

\section{INTRODUCTION}

The prevalence of digitalization of operations, systems, and supply chains is becoming the new reality of today [1] [2]. Albeit the concern whether digital transformation is a new buzzword or it is truly contributing to adding value to the different business stakeholders.

There are various challenges in managing the digital transformation, they escalate when businesses operate globally to realize complex capital projects; where high levels of uncertainty and global market challenges directs businesses to establish strategies ensuring a greater flexibility, efficiency and effectiveness.
In the past decade, large capital projects often suffered poor performance, such as time delays of $20 \%$ as compared to their original schedule, and they often incurred cost overruns, up to $80 \%$ of their original budgets [3]. This critical situation drives many organizations that run complex capital projects (referred to hereinafter as project-based organizations) to adopt digitalization in their supply and value chain, desperately hoping to reverse the capital losses and regain competitiveness.

In this study we seek to answer the following research questions; (i) what is the scope, strategic motivation and challenges of implementing digital transformation in the capital projects supply chains, and (ii) why and how project-based organizations innovate to digitally transform their supply chains.

The research design follows a two-steps approach. A systematic literature review is conducted, followed by a series of explorative interviews with senior executives of major project-based organizations worldwide. This paper focuses on reporting the results from the first step whilst the second phase of the research is still in progress. From the literature, six primary elements are identified and grouped to form a conceptual model; answering the questions of why, how, by what, and where project-based organizations digitally transform their operations and supply chains.

The elements of the conceptual model address the scope of the digital transformation process; the corporate and 
operational strategic motivations behind adopting digital innovations, the adopted technologies and expected impact of implementing digitalization. Further, our conceptual model addresses the degree of readiness to digitally transform projectbased organizations, by preparing their human capital, and considering the potential enablers and barriers. Hence, the model helps identifying the necessary capabilities to survive the transition and manage post-transition phases.

From the interviews, we observe a continuum of digital transformation in project-based organizations. Whilst many of them are lagging in adopting digitalization or in implementing digital transformation of their operations and supply chains (e.g., those delivering EPC projects - EngineeringProcurement-Construction), a few of them are among the early adopters (e.g., those delivering defense, space and aerospace capital projects).

The present research contributes to the existing knowledge base by developing an empirically validated model for the project-based organizations to continuously generate an added value, whilst managing complex systems (i.e., capital projects). Hence, identifying the required capabilities for transforming supply chains when operating with capital investments and a large supply base, in the face of unprecedented levels of uncertainty.

\section{METHODOLOGY}

Although the research on digital transformation is rapidly growing, yet it is still in its infancy. Academic resources investigating the process of digital transformation are scant, specifically in the domain of project-based organizations. Many of the available sources are published in information technology and computer research journals; hence, they are investigating digital transformation from a technological innovation viewpoint and rather focusing on the technology not on the operations and supply chain management issues. Further, there is a plethora of practice-oriented contributions developed in consultancy houses and practitioner reports. Hence, the available body of knowledge on digital transformation appears to be fragmented and published in dispersed sources.

In light of the above, the present research is designed following two-steps approach. First, a systematic literature review is applied as a methodology best suited for answering the 'what' 'how' and 'why' questions in supply chain management research [3]. Second, individual semi-structured interviews were conducted with a group of senior executives of project-based organizations. The executive senior managers are carefully selected key informants; their decision-making involvement allow them to strategize the transitioning process while they oversee their business operations and the supply chain.

\section{A. Literature Search}

To overcome the lack of academic resources of such new phenomenon in the project-based organizations, the literature search was performed by marrying two domains; first, the capital projects domain, and second, the supply chain domain as depicted in Fig.1.
Literature search phase is performed twice; 1) to build a solid academic base regarding the capital project supply chain digital transformation, on which to develop the Systematic Literature Review; 2) to gather information regarding the digital transformation of the supply chain in general. This second phase consisted of exploring the literature related to the digitalization of any kind of supply chain, observing the schemes and main dimensions that have been already used by other authors in their systematization work. The aim is to validate the initial theoretical framework.

The literature search for capital projects digital transformation is performed based on a set of keywords and inclusion/exclusion criteria defined a priori. The keywords selected are: "Capital projects" OR "EPC" OR "Projects" OR "ETO" AND "Digital transformation". "Capital projects" OR "EPC" OR "Projects" OR "ETO" AND "Innovation". The literature search for supply chain digital transformation is performed based on the following set of key words: "Supply Chain" OR "ETO Supply Chain" AND "Digital transformation" AND "Innovation".

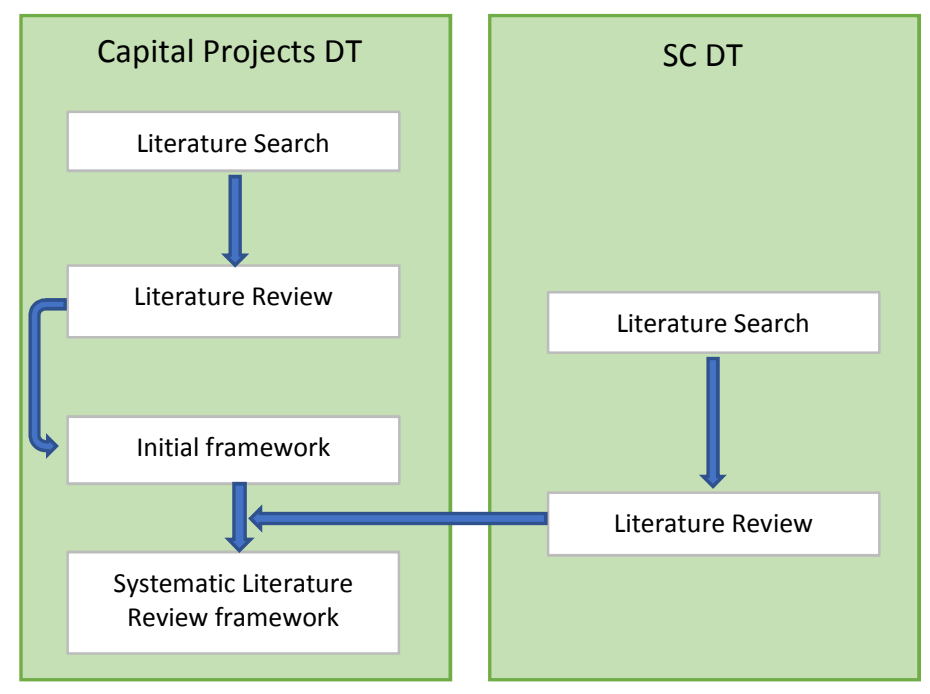

Fig. 1. Literature Review Process

Following the guidelines of [3], the inclusion criteria are crafted to ensure the inclusion of the papers that fit with the scope of the initial theoretical framework (i.e., strictly related to capital projects, supply chain, digital transformation and innovation). Due to the newness of the phenomenon, the year 2010 as a publication date was set to rough cut the primary sample. Further, all publications have to be in English language as it is the main prevalent scientific language in the supply chain domain.

The total number of papers that appeared in the capital projects supply chain search results is 1163 academic articles and 15 consultancy house papers. The number of academic articles selected after applying the inclusion and exclusion criteria are 10 for the capital projects digital transformation and 16 for the supply chain digital transformation.

To avoid potential sampling and selection bias, the final selection of the synthesis sample was performed by involving three independent researchers. The following two filtering 
processes were applied; first, a rough cut based on reading the title and abstract of the search results to exclude papers that are completely out of the scope of our study. Second filtering is based on a swift skim-through and reading the full paper to exclude those that do not entirely cover the theoretical framework.

The literature collection was done primary using SCOPUS database. Due to the novelty of the search topic, a decision was made to perform a parallel search on Google database to include prominent practitioner's and notable consultancy houses reports.

\section{FINDINGS}

We created a theoretical (systematic literature review) framework to serve as data extraction and storing database and afterwards it will be used to systematically depict, categorize and compare the relationships and the contextual environment of managing digital transformation in project-based organizations. This framework is carefully designed to collect the insights of each document, and to answer the why, how, where, and what questions. It addresses the following dimensions; A) Impacts, B) Strategic motivations, C) Supply Chain locus, D) Strategic decisions to face digital transformation, E) Operational decisions to face digital transformation, F) Enabling factors and barriers, G) Change management before, during and after the transformation, $\mathrm{H}$ ) Challenges and I) Contextual information (i.e., the size, role, global footprint and sector in which the project-based actor mentioned in the document is active). A critical review is structured to analyze the outlined key concepts. The major insights of each key concept are reported as follows:

\section{A. Impacts}

The Impacts are the consequences of the digital transformation on the capital projects supply chain. We have mainly focused on the impacts caused by disruptive technologies and solutions, such as data management platforms and cloud services [4] [5] [6]. These tools are to improve visibility and connectivity along the supply chain as well as efficiency. Proper data management is an opportunity to create a knowledge architecture, allowing the company's access to its "silent archives" [4]. This means that all the currently tacit knowledge that constitutes the firm know-how and intellectual assets may be managed more efficiently by means of Big Data and analytics.

Digital transformation is believed to improve business performance; a firm that is integrating the digital transformation within its strategic plan would be able to reduce non-valueadding activities, improve reliability, reduce project costs by roughly $45 \%$ and gain productivity across almost all project lifecycle phases [7].

Of course, there are risks that discourage top management to adopt digital transformation. These are mainly due to uncertainties embedded in the capital projects domain, caused by the need of coping with international and diverse project portfolios [5].

\section{B. Supply Chain locus}

The capital projects supply chain is composed of different phases - that is, the bidding phase, design and engineering, procurement and operations [8]. In this study we attempt to understand which phases are mostly exposed to digital transformation. While some innovative technologies, like the BIM (Building Information Modeling), are actually exploited to coordinate all the phases of the project life-cycle [9] [10], some aspects of the digital transformation may be specific to single phases. However, perhaps due to the novelty of the topic and the lack of digitally mature organizations, information regarding where the digital transformation is taking place in the Supply Chain are scarcely present in the literature.

\section{Strategic motivations}

The insights related to strategic motivations for embracing the digital transformation can be grouped into two categories: operative (short-term) and strategic (long-term) advantages.

Reduced time to market and lower costs can be quick-win achievements for firms that plan to digitalize: the adoption of Cloud-based solutions in capital projects improve sourcing and procurement performances, supporting collaboration, analytic and mobility services [5] [10]. In addition, cost barriers to afford innovative technological solutions are now falling, encouraging firms to go digital [11]. Moreover, investments for innovating and integrating new technologies is crucial for staying competitive [7].

When taking a long-term perspective, it is key to see digitalization as a means to solve the complexity of capital projects [4]. Hence, to improve the performances, and flexibility of project-based organizations under different or rapidly evolving scenarios. Moreover, the adoption of certain technologies is now considered a "market qualifier", i.e. "a criterion that a firm must exhibit to be a viable competitor in the marketplace" [12]. The leadership of project-based organization needs to support all the employees by initiating internal dialogue to discuss innovation and to adopt a flexible thinking in order to absorb and integrate its principles. To do so, leaders need high awareness of the company pain-points in order to directly address them [7]. What really drives change are the desires of supporting cross-project learning and capability building, aiming at gaining long-term economic benefits in future projects [12].

There are two relevant issues for EPC supply chain actors that contribute to motivate firms to face the digital transformation. First, productivity gaps and information inefficiencies "open the door to new entrants in the space", socalled disruptors, that threaten to overtake the traditional companies of this sector that have recently slowed down in innovating [13]. On the other hand, the impact of regulation is very binding in the construction industry, sometimes excessively, although it may lead to more socially responsible organizations in terms of environment, health and safety [12]. In addition, large projects typically show $20 \%$ time delays and are up to $80 \%$ over budget, showing a clear need for innovation [14]. 


\section{Operational decisions to face digital transformation}

In order to manage the transition phase, there are specific activities that need to be planned in designing the steps for digital transformation. This may result in adopting new disrupting technologies, or in organizing targeted training courses [11]. In this regard, the literature mainly touch on three aspects: the technological improvement, the operative improvement and the executive improvement.

Portfolio management, for example, can be optimized by means of cloud-based analytics, in collaboration with some tools to assess and manage an organization's portfolio of capital projects [15].

Many authors agree on considering coordination along the supply chain as a major issue in the EPC sector [7]. A consistent and comprehensive framework for the company's needs and goals could help in managing project planning and execution more smoothly. On the other hand, it is believed that companies should directly focus on building a digitally-enabled new business model [6]. Moreover, what really matters is that information has to be shared along the supply chain by every stakeholder transparently [14].

\section{E. Strategic decisions to face digital transformation}

Strategic decisions are the choices to be taken along the path towards the company's vision of development and maturity.

In this case, the three main facets addressed by the authors are how the technological improvement, the operative improvement and the executive improvement are to be taken into consideration at a strategic level.

One important point related to the operative improvement involves the organization's ability to absorb innovation. There probably is a higher degree of complexity in integrating digital solutions effectively in the organization. According to many authors, visualization, IoT and analytics, for example, can contribute to the improvement of construction workers productivity and safety [7].

\section{F. Enabling factors and barriers}

The literature highlights different factors that act as enablers or barriers to the digital transformation [6] [8] [16] [17]. Mostly, these factors are internal to the organization. With these regards, clear communication, alignment around priorities and the creation of a learning environment are widely considered to be key enabling factors [16].

On the other hand, the most significant barriers are cost constraints, in addition to the so-called Not-Invented-Here (NIH) syndrome. These two elements are related to the disproportionate share of risk that characterizes the capital project sector and the EPC business in particular [15]. Moreover, the lack of support from the leaders of the company obviously is the most critical barrier that must be faced [7].

\section{G. Change management before, during and after the transformation}

Managing change within the organization may be the foremost challenge when implementing the digital transformation. The Framework has been designed a priori to gather insights regarding change management at each step of the transition: before, during and after the transformation.

The literature mainly faces three concepts related to the change management: change with people, processes and tools [13]. The beginning of a transition process is the awareness that there is an issue in the organization. Such issue can be faced in many ways, including "softer" methods that signal change, such as altering the language used, restructuring the office environment, breaking down silos within organizations through company-wide competitions, and enhancing the interaction of senior managers with operational staff [18].

\section{H. Challenges}

The challenges that a firm has to face when implementing the digital transformation are both internal to the organization and external, i.e. at a supply chain level. Among the most relevant challenges, is the change of the organizational culture, and the need to develop organizational capabilities and structures to support wide-scale innovation [14].

Firms have to fight against poor control on the processes, low productivity and issues with the alignment of each employee to the digital strategy. On the other hand, challenges at a supply chain level are just as relevant. Among all, it is worth mentioning the software incompatibility between different partners and actors in the supply chain, the geographic spread of the project portfolio and a fragmented, risky context [4].

\section{Contextual information}

As reported in Fig. 3, the majority of the documents included in the literature search referred to the construction sector, proving that there is already considerable interest in the digital transformation of capital project supply chains [6] [7] [8] [9] [10] [11] [12] [14] [17] [20] [21].

The specific role of project-based organizations is an additional contextual information related to the EPC contractors. As depicted in Fig. 4, however, most articles do not explicitly refer to a specific firm [6] [7] [11] [12] [20].
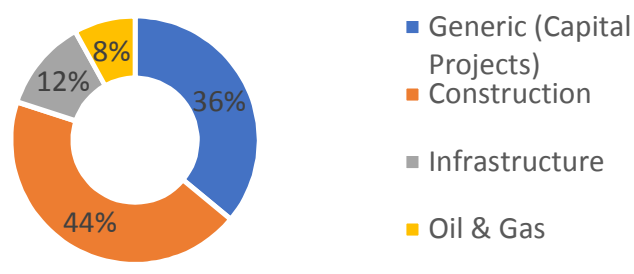

Fig. 2. Results for the projects sector analysed in each document 


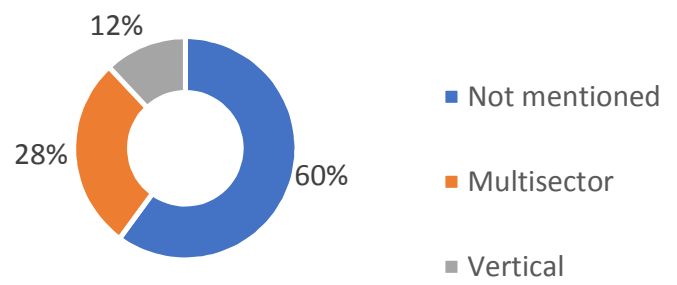

Fig. 3. Results for the role of the EPC contractor role analysed in each document

\section{INITIAL CONCEPTUAL FRAMEWORK}

Exploring digital transformation in the capital projects supply chain is a challenging task, because of both the novelty of the concept and the fragmented nature of the current body of knowledge.

From the literature - based on the six elements of impacts, locus, strategic motivation, change, technologies and barriers we developed a preliminary model for the digital transformation of capital projects supply chains, depicted in Fig. 5. The model guides project-based organizations to develop their digital transformation strategy by first identifying the strategic priorities and the sought-after benefits.

Benefits and strategic priorities are linked considering a direct interaction between the strategic decisions taken at the beginning of the transition. As such, the transition and posttransition phases will be reversely planned so that organizations can start digitalizing with an end-goal in mind. This step is affected by the external context, i.e. the business type, the enabling factors and barriers to transformation, which are considered contextual factors having an impact on the digital strategy.

Two steps need to be performed simultaneously, once the digital transformation is considered part of the firm's strategic objectives, and the digital strategy is agreed upon. First, designing the technological solution/s by focusing on where in the project life-cycle or which supply chain phase is more appropriate to digitalize. Second, developing and implementing a plan for change management - that is, investing and preparing the human capital to be part of the transformation. This can be done by enhancing a company-wide engagement in the brainstorming for the digital transformation. These practices can enable a successful change, and overcome the challenges of managing the internal organization for supporting change.

The success of digital transformation depends on developing the proper organizational capabilities that help managing the transition and post-transition phases, whilst preserving the organization's core competence and continuously generating an added value.

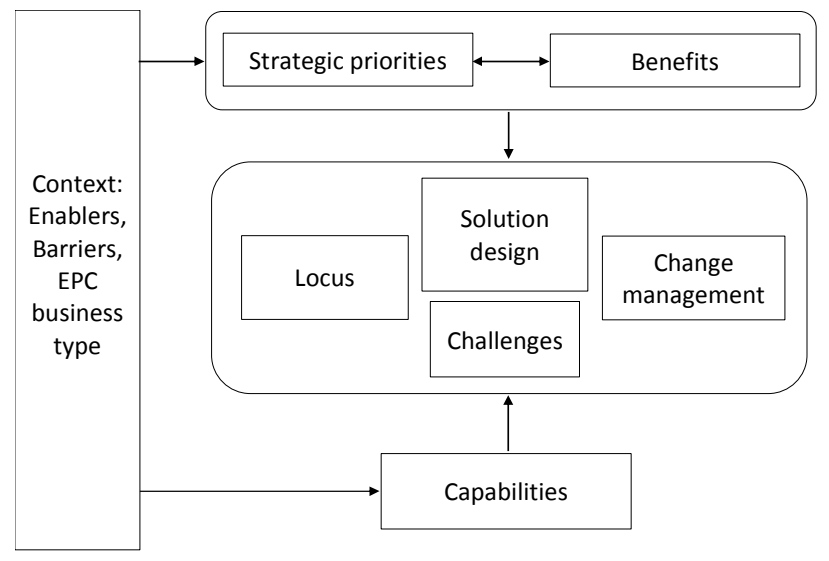

Fig. 4. Initial coceptual model for managing digital transofrmation of capital projects supply chains

\section{CONCLUSION}

This research contributes to the theory and practice of supply chain digital transformation in the context of capital projects. First, this study addresses the fragmented nature of the digital transformation body of knowledge, by systematically reviewing capital projects and supply chain digital transformation literature. As a result, we identify from the literature six elements grouped in a novel conceptual model that addresses designing the scope of the digital transformation, and managing the transition phase. Further, this study proposes that success of digital transformation is dependent on developing capabilities that enable organizations to exploit the potential benefits of the technology implementation whilst keep managing their core value-adding activities. As such, we propose that the value proposition should be continuously adjusted in relation to the strategic priorities and the capabilities.

Second, our conceptual model contributes to practice by guiding project-based organizations managing the transition and post-transition phases. By first reflecting on the organization's strategic priorities, understanding what are the potential impacts of the digital transformation on the operations, which phases of the project and of the supply chain that are most suited to undergo the transformation, identifying which technology shall be adopted and examining the interaction with the human capital or any other potential challenges.

This is an ongoing research; our next step is to continue the analyses of the interviews with senior supply chain executives so as to provide a refined and tested conceptual framework.

There are three main concepts keep recurring in the findings, which can be important in designing a digital transformation process in project-based organizations. These outlined concepts intersect and are interrelated, they yet need further investigation in future research. First, the relevance of bridging the gap among different actors in the fragmented capital projects supply chain. The degree of digital readiness 
can significantly vary among the supply chain actors. Second, the capability of being ready to adopt new technologies. Third, the importance of developing human capital for the digital era and a collective mind-set towards organizational change.

\section{REFERENCES}

[1] Wieland, A., Handfield, R. B., and Durach, C. F. "Mapping the Landscape of Future Research Themes in Supply Chain Management" J. Bus Log, Vol 37, No.3, pp.205-2012, 2016.

[2] Goldsby, T. J., and Zinn, W. "Technology Innovation and New Business Models: Can Logistics and Supply Chain Research Accelerate the Evolution?” J. Bus Log, Vol. 37, No. 2, pp.80-81, 2016.

[3] Durach, F., Kembro, J. and Wieland, A. "A new paradigm for systematic literature reviews in supply chain management." J. Supply Chain Management, 2017.

[4] Concord Project Technologies, "A Digital Transformation Roadmap for Your Capital Project Organization", 2017.

[5] Accenture, "Digital Capital Projects", 2018.

[6] Gagliardi (Digital Practice), "Digital transformation in the construction and engineering industry", Part II, 2017.

[7] Bentley, Blanco, Fuchs, Parson, Ribeirinho, Fuchs, Nowicke, Strube (McKinsey), "Harnessing the promise of digital", Vol. "Voices on Infrastructure", 2018.

[8] Gerbert, Castagnino, Rothballer (The Boston Consulting Group), "How Technology Is Revolutionizing Construction", 2016.

[9] Cao D., Li H., Wang G., Huang T., "Identifying and contextualising the motivations for BIM implementation in construction projectsAn empirical study in China", Vol. 35, pp.658-669, 2017.

[10] Supe (Capgemini), "EPCM 4.0 - The Next Big Thing in Engineering and Construction", 2017.

[11] Gerbert, Castagnino, Rothballer, Renz, Filitz (The Boston Consulting Group), "Digital in Engineering and Construction: The Transformative Power of Building Information Modeling”, 2016.

[12] Wang, Gosling, Kumar, Naim, "Accelerating BIM adoption in the supply chain", 2017.

[13] Schwartz R., Amaba B., "Innovation program deployment for industries with irreversible processes", pp.427-431, 2017.

[14] Agarwal, R., Chandrasekaran, S., Sridhar, M., 'Imagining construction's digital future', McKinsey Productivity Sciences Center, Singapore, 2016.

[15] Fuchs, Nowicke, Strube (McKinsey), "Navigating the digital future: The disruption of capital projects", 2017.

[16] Toole T.M., Chinowsky P., Hallowell M.R., "A tool for improving construction organizations' innovation capabilities", pp.727-736, 2010.

[17] Pellicer E., Yepes V., Correa C.L., Alarcón L.F., "Model for systematic innovation in construction companies [Modelo para la Innovación Sistemática en Empresas Constructoras]", J. of Construction Engineering and Management,Vol. 140, 2014.

[18] Bilefield, Seitz (McKinsey), "Digital transformation: The three steps to success", 2016.

[19] Broadhead, Murchú, Lavery, Walker (PWC), "Reimagining capital projects: Transformation of capital projects through the use of digital technologies", 2016.

[20] Davis P., Gajendran T., Vaughan J., Owi T., "Assessing construction innovation: Theoretical and practical perspectives", Vol. 16, No. 3, pp. 104-115, 2016.

[21] Forsman S., Björngrim N., Bystedt A., Laitila L., Bomark P., Öhman M., "Need for innovation in supplying engineer-to-order joinery products to construction: A case study in Sweden”, Vol. 12, No. 4, pp. 464-491, 2012. 